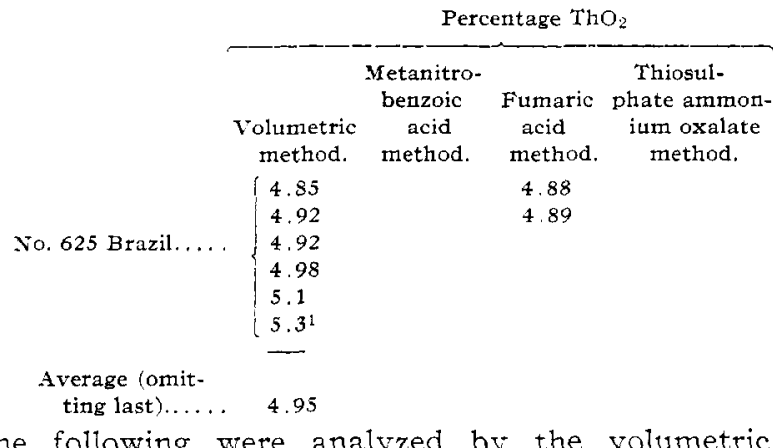

The following were analyzed by the volumetric method but not checked by other methods:

No. 626
North Carolina.
4.84
4.84
No. 631 North Carolina. 5.11 5.11

CONCLUSIONS.

I. At room temperature thorium is precipitated quantitatively from a cold acetic acid solution ( 20 cc. glacial acetic acid and $300 \mathrm{cc}$. water) by means of ammonium molybdate.

2. Other rare earths found in monazite sand are not precipitated under the conditions defined in "I."

3. The ratio of thorium to molybdenum ( $1: 2.017$ and $I: 203$ ) indicates that the precipitate is a normal thorium molybdate.

4. By observing proper conditions of acidity, thorium may be accurately titrated by means of ammonium. molybdate. Other rare earths have no effect on this titration.

CONTRIBUTION NO, 207, HAVEMEYER LABORATORIES, COlumbia UNIVERSITY.

\section{THE RESENES OF RESINS AND OLEORESINS.}

By Chas. H. Herty and W. S. Dickson. Received February 1, 1912.

The oleoresinous exudate of pine trees, commonly called "crude turpentine," consists of a mixture of a volatile oil, acids and unsaponifiable matter. On distillation with steam the volatile oil, "spirits of turpentine," passes off; the residual resin, freed from excess of water by heating, solidifies on cooling and constitutes commercial "rosin." The name "resene" has been applied by Tschirch" to the non-volatile, unsaponifiable constituent of such resins and oleoresins.

Though the composition of crude turpentine varies considerably in different specimens, an average analysis of specimens collected by the usual commercial methods would show approximately:

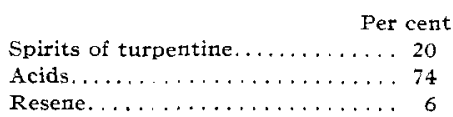

Resenes, according to their origin, show varying physical states, some being colorless solids while many are very viscous liquids, extremely sticky and non-crystallizable. They are composed of carbon, hydrogen and oxygen, but the per cent. of oxygen is usually smaller than in the accompanying acids. Toward reagents they are very resistant, especially

1 The authors are unable to account for this high result.

2 Tschirch, "Die Harze und die Harzbehäeter," Second edition, p. 1079. toward alkalies. Although containing oxygen, they show, according to Tschirch, ${ }^{\text {I }}$ none of the usual reactions indicating the presence of hydroxyl, carboxyl. aldehyde or ketone oxygen, nor are they ethereal salts or lactones. Tschirch inclines to the view that they belong to the class of oxyterpenes or oxypolyterpenes.

While much work has been done upon the volatile oils and the acids of oleoresins, little attention has been paid to the resenes, except ultimate analyses and approximate statements of the proportion present in isolated specimens studied. In connection with an investigation carried out in this laboratory in collaboration with the United States Forest Service, there remained a large number of specimens of resin from well identified individual trees growing in Florida. It seemed desirable, therefore, to study more closely the question of the proportions of resene in these specimens. The investigation was extended to the resins of conifers growing near this laboratory, and to specimens collected in other countries. Finally the amount of resene was determined in several oleoresins obtained in perfectly fresh condition from individual trees in Florida. These specimens were collected from the two species of pines from which crude turpentine is commercially obtained in this country, Pinus Palustris, (Longleaf Pine) and Pinus Heterophylla (Cuban or Slash Pine).

The resins were prepared by distilling the oleoresins in a current of steam slightly superheated, the temperature being raised to $140^{\circ} \mathrm{C}$. toward the end of the distillation. After complete removal of the volatile oil, the residue was kept at $140^{\circ} \mathrm{C}$. in the oil bath surrounding the distillation flask until all water was driven off. The molten resin was then filtered through absorbent cotton and cooled to solidification in glass or iron molds.

The determination of resene in the resins was carried out in the usual manner. The weighed specimen, about two grams, was dissolved in a considerable excess of $N / 2$ alcoholic potassium hydroxide, allowed to stand at room temperature eighteen hours, diluted with water until separation of the resene began and the solution cleared by the addition of a small quantity of ninety-five per cent. alcohol. This solution was then extracted three times with petroleum ether, boiling below $40^{\circ}$. The combined extracts were shaken out with fifty per cent. alcohol to remove slight amounts of dissolved potassium salts of resin acids. After drawing off the petroleum ether extract into a weighed glass evaporating dish, it was allowed to evaporate spontaneously to constant weight.

In the case of the oleoresins, after spontaneous evaporation of most of the petroleum ether the residue was heated for five hours on a steam bath in order to remove completely the petroleum ether and the volatile oil. Considerable difficulty was experienced at the outset in these evaporations due to the tendency of the material to "crawl" over the rim of the vessel.

1 Loc. cit. 
This was entirely overcome by using a thin coating of vaseline on the rim of the vessel.

The following results were obtained:

TAble I.-Per Cent. of Resene in Resins from Different Species.

\begin{tabular}{lllr} 
Species. & Local name. & Origin. & $\begin{array}{r}\text { Per cent. } \\
\text { resene. }\end{array}$ \\
Pinus Taeda & Loblolly Pine & North Carolina & 4.10 \\
Palustris & Longleaf Pine & Florida & 5.67 \\
" Maritima & Maritime Pine & France & 7.37 \\
" Heterophylla & Cuban or Slash Pine & Florida & 7.38 \\
" Serotina & Pond Pine & Florida & 7.65 \\
" Echinata & Old Field Pine & North Carolina & 8.71 \\
" Species unknown & Central America & 8.94 \\
" Sabiniana & Digger Pine & California & 9.66 \\
\hline
\end{tabular}

In order to test the variation of the amount of resene in trees of the same species two sets of determinations were carried out on trees of different diameters. The results follow:

Table II.-Pinus Palustris (Longleaf Pine).

$\begin{array}{ccc}\text { Tree no. } & \begin{array}{c}\text { Diameter } \\ \text { (inches) }\end{array} & \begin{array}{c}\text { Per cent. resene } \\ \text { in resin. }\end{array} \\ 1 & 7.3 & 5.26 \\ 2 & 15.0 & 5.95 \\ 3 & 21.0 & 9.68 \\ 4 & 13.0 & 7.45 \\ 5 & 8.7 & 5.67 \\ 6 & 9.0 & 5.45 \\ 7 & 13.5 & 6.22\end{array}$

Table III.-Pinus Heterophylla (Cuban or Slash Pine).

$\begin{array}{crr}\text { Tree no. } & \begin{array}{r}\text { Diameter } \\ \text { (inches) }\end{array} & \begin{array}{r}\text { Per cent. r } \\ \text { in resin. }\end{array} \\ 1 & 7.0 & 7.87 \\ 2 & 14.5 & 7.36 \\ 3 & 24.5 & 7.20 \\ 4 & 12.3 & 7.25 \\ 5 & 8.2 & 6.58 \\ 6 & 13.0 & 7.84 \\ 7 & 9.0 & 7.00\end{array}$

To determine possible variations in the per cent. of the resene in different seasons of the same year two trees were selected, one each, Pinus Palustris, tree No. 2, Table II, and Pinus Heterophylla, tree No. 2, Table III. Beginning in the early Spring the oleoresins were collected from these at regular periods of four weeks until the close of the season in the Fall. From the resins prepared from these specimens the following results were obtained:

\begin{tabular}{ccc} 
& \multicolumn{2}{c}{$\begin{array}{c}\text { Tabiz IV. } \\
\text { Per cent. resene in resin from }\end{array}$} \\
\cline { 2 - 3 } Collection no. & Pinus Palustris. & $\begin{array}{c}\text { Pinus Heterophylla. } \\
1\end{array}$ \\
2 & 5.31 & 7.36 \\
3 & 5.44 & 7.67 \\
4 & 5.95 & 7.23 \\
5 & 6.02 & 8.17 \\
6 & 6.09 & 7.38 \\
7 & 6.53 & 7.43 \\
& 5.24 & 7.77
\end{tabular}

It is scarcely probable that in the case of Pinus Palustris any significance is to be attached to the gradual increase in the per cent. of resene as the season advanced until the last collection.

Further determinations were made of the per cent. of resene in specimens of oleoresin collected with great care in Florida and promptly analyzed. The following results were obtained:

$$
\text { TABZE V. }
$$

Pèr cent. tesene in oleoresin of

$\begin{array}{ccc} & \text { Pree no. Pinus Palustris. Pinus Heterophylla. } \\ 1 & 7.10 & 6.83 \\ 2 & 3.84 & 6.76 \\ 3 & 7.33 & 6.96\end{array}$

Finally, a specimen of "scrape" (Gum Thus) was obtained from a Longleaf pine (Pinus Palustris). This scrape is the hardened mass which gradually collects on the scarified surface of the tree as a result of the crystallization of the resin acids of the oleoresin. It receives its name from the fact that at the end of the season it is scraped from the surface of the trees by means of a sharp tool. It contains approximately one-half as much spirits of turpentine as the ordinary oleoresin collected from the receptacles. The resin was prepared from this scrape by distillation with steam as above. On analysis it showed 3. I4 per cent. of resene.

In continuation of this work, there is now being carried out in this laboratory an investigation of the composition of the resene of Pinus Heterophylla.

tniversity of Norti Carolina.

\section{A METHOD OF EXAMINING CHINA WOOD OIL. By PARker C. Mcilhiney. \\ Received April 2, 1912.}

The examination of china wood oil to determine its quality and to detect the presence of foreign oil presents several difficulties. The iodine figure is not far removed from that of several other oils, the saponification figure is identical with that of many others and although the specific gravity and the refractive index are higher than those of almast any other fatty oil, the difference in these respects from some other oils is not sufficiently great to furnish satisfactory data in all cases.

The most marked characteristic of china wood oil is its property of solidifying readily under the influence of heat or when acted upon by iodine. Heating the oil to a temperature of from $240-280^{\circ} \mathrm{C}$. and noting the readiness with which the oil jellies and the consistency of the jelly produced have been extensively used as commercial tests for grading the oil. It is difficult, however, to conduct such a test under conditions which will give numerical values to the results, these being usually stated in terms of the apparent hardness or softness of the jelly, or else in terms of the number of minutes required to jelly at some given temperature. The latter method is open to several serious objections and it is difficult to reproduce in a second experiment the conditions of the first.

The behavior of the oil when iodine dissolved in a suitable solvent is added to it, furnishes a well known qualitative method of identifying china wood oil and particularly of distinguishing it from linseed oil, but since the test as usually carried out gives merely a jelly, no quantitative results are obtainable from them.

It was thought that if this test could be made quantitative so that a separation could be effected between the solidified and the liquid resulting from the action of iodine upon the oil, a valuable and quantitative method of testing the oil might be obtained, particularly as such a test would be directly related to the most important and characteristic property of the oil. A series of experiments conducted with this end in view showed that acetic acid of $99^{x} / 2$ per cent. strength or thereabouts was a solvent in which 